\title{
Heritable pulmonary hypertension: from bench to bedside
}

\author{
Barbara Girerd ${ }^{1,2,3}$, Jason Weatherald ${ }^{1,2,3,4}$, David Montani ${ }^{1,2,3}$ and \\ Marc Humbert ${ }^{1,2,3}$
}

Affiliations: ${ }^{1}$ Faculté de Médecine, Université Paris-Sud, Université Paris-Saclay, Le Kremlin-Bicêtre, France. ${ }^{2}$ Service de Pneumologie, Centre de Référence de l'Hypertension Pulmonaire, Hôpital Bicêtre (Assistance Publique Hôpitaux de Paris), Le Kremlin-Bicêtre, France. ${ }^{3}$ Inserm UMR-S 999, Hôpital Marie Lannelongue, Le Plessis Robinson, France. ${ }^{4}$ University of Calgary, Dept of Medicine, Division of Respirology, Calgary, AB, Canada.

Correspondence: Marc Humbert, Université Paris-Sud, Service de Pneumologie, Hôpital Bicêtre, 78 Rue du général Leclerc, 94270 Le Kremlin-Bicêtre, France. E-mail: marc.humbertđaphp.fr

@ERSpublications

Genetic counselling and testing available in France for patients at risk of $\mathrm{PAH}$ and PVOD/PCH http://ow.ly/m0MA30dBnkF

Cite this article as: Girerd B, Weatherald J, Montani D, et al. Heritable pulmonary hypertension: from bench to bedside. Eur Respir Rev 2017; 26: 170037 [https://doi.org/10.1183/16000617.0037-2017].

ABSTRACT Mutations in the BMPR2 gene, and more rarely in ACVRL1, endoglin, caveolin-1, KCNK3 and $T B X 4$ genes predispose to heritable pulmonary arterial hypertension, an autosomal dominant disease with incomplete penetrance. Bi-allelic mutations in the EIF2AK4 gene predispose to heritable pulmonary veno-occlusive disease/pulmonary capillary haemangiomatosis, an autosomal recessive disease with an unknown penetrance.

In France, the national pulmonary hypertension referral centre offers genetic counselling and testing to adults and children. Predictive testing is also proposed to adult relatives at risk of carrying a predisposing mutation. In that context, we offer all asymptomatic BMPR2 mutation carriers a programme to detect pulmonary arterial hypertension at an early phase, as recommended by the 2015 European Society Society of Cardiology/European Respiratory Society pulmonary hypertension guidelines. Finally, pre-implantation genetic diagnosis has been conducted on five embryos from two couples in which the fathers were carriers of a pathogenic BMPR2 mutation.

\section{Historical timeline}

Heritable pulmonary arterial hypertension

The study of genetics in pulmonary hypertension began in 1954 when DRESDALE et al. [1] first described familial pulmonary arterial hypertension $(\mathrm{PAH})$, suggesting the potential role of genetic defects in the development of the disease. Before the availability of modern genetic tools, genealogic studies allowed us to understand the genetic transmission of heritable PAH. In 1984, it was known that heritable PAH segregates as an autosomal dominant trait with incomplete penetrance [2]. In 1997, linkage analysis in affected families allowed NichOLs et al. [3] and MORSE et al. [4], independently, to localise the locus

Received: March 302017 | Accepted after revision: June 022017

Support statement: J. Weatherald is the recipient of a joint European Respiratory Society/Canadian Thoracic Society Long-Term Research Fellowship (LTRF 2015-4780). Funding information for this article has been deposited with the Crossref Funder Registry.

Conflict of interest: Disclosures can be found alongside this article at err.ersjournals.com

Provenance: Publication of this peer-reviewed article was sponsored by Boehringer Ingelheim Pharma GmbH \& Co. KG, Ingelheim am Rhein, Germany (principal sponsor, European Respiratory Review issue 145).

Copyright CERS 2017. ERR articles are open access and distributed under the terms of the Creative Commons Attribution Non-Commercial Licence 4.0 
implicated in PAH development on chromosome 2. Candidate genes in this region were then identified and mutations in the bone morphogenetic protein receptor type 2 (BMPR2) gene were found in $\mathrm{PAH}$ patients (figure 1) $[5,6]$. Additional genetic analyses revealed that $3.5-40 \%$ of sporadic PAH patients [7-13] and 9-22.5\% of anorexigen-associated PAH patients carried a mutation in this main gene $[14,15]$.

In 2003, the development of PAH in patients with hereditary haemorrhagic telangiectasia (HHT) led to the identification of two other PAH-predisposing genes: activin A receptor type II-like kinase 1 (ACVRL1 or ALK1) and endoglin (ENG) (figure 1). The BMPR2, ACVRL1 and endoglin gene products are involved in the transforming growth factor (TGF) $\beta$ signalling pathway. In fact, proteins encoded by BMPR2 and $A C V R L 1$ genes form a heteromeric complex which associates with endoglin [7]. The cardinal features of HHT are mucocutaneous telangiectasias, recurrent epistaxis, macroscopic arteriovenous malformations (particularly in the pulmonary, hepatic and cerebral circulation) and, in rare cases, PAH may occur. HHT has an autosomal dominant transmission with late onset and essentially complete penetrance (97\%) by the age of 60 years. There are several potential mechanisms by which pulmonary hypertension can develop in HHT patients. Pulmonary arteriovenous malformations are frequent in HHT, often resulting in clinically significant right-to-left shunts which cause hypoxemia, paradoxical embolism, stroke and cerebral abscesses [16-19]. Arteriovenous malformations in the systemic circulation cause left-to-right shunts, resulting in a hyperkinetic state and high-output heart failure. However, precapillary PAH can also occur in HHT patients, with remodelling of small pulmonary arteries and similar histological lesions to those observed in idiopathic PAH or PAH due to BMPR2 mutations [20-22]. There are several studies reporting an association of ACVRL1 mutations and PAH in HHT patients without any other cause of pulmonary

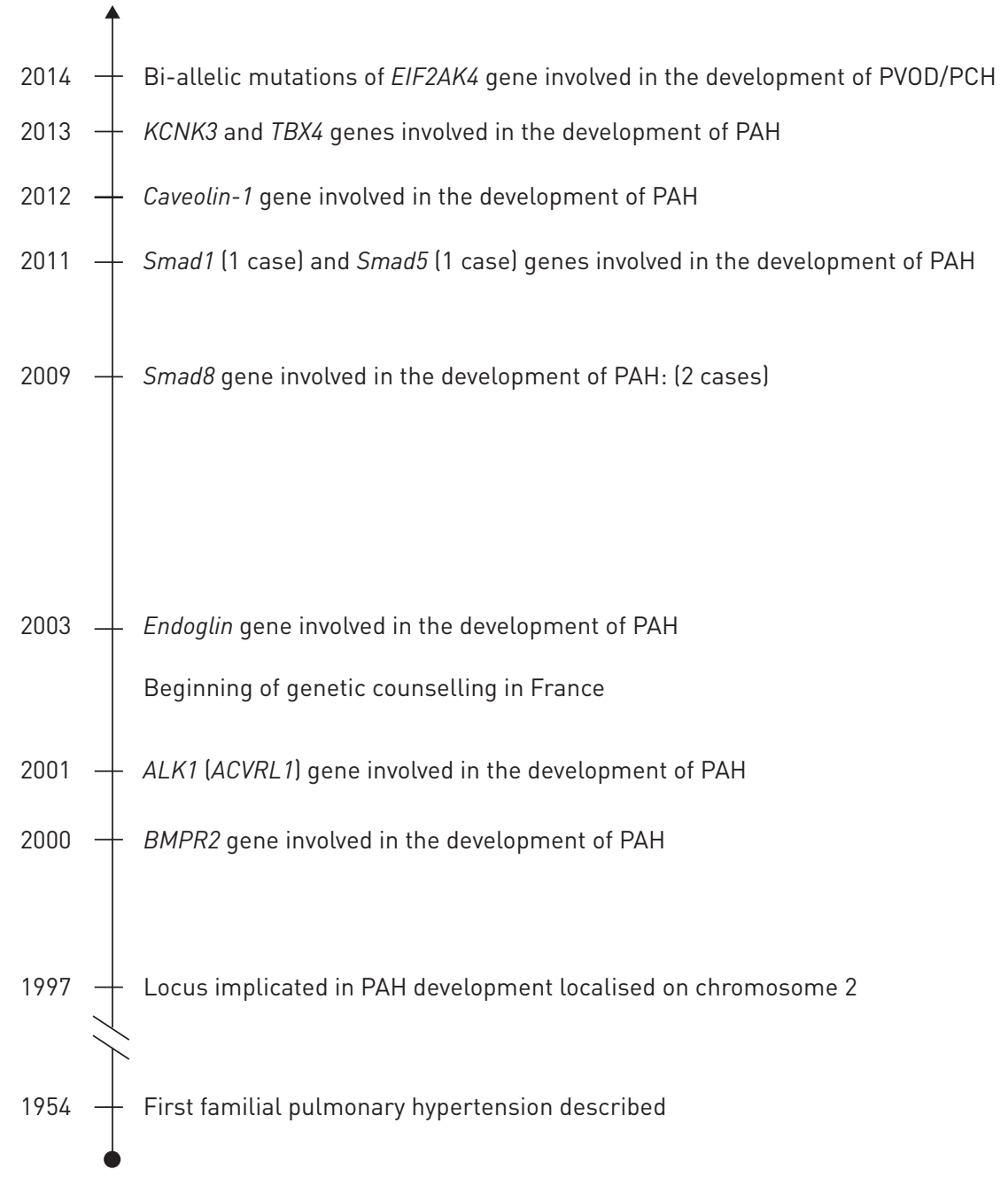

FIGURE 1 Historical timeline showing the main dates of genetic discovery in heritable pulmonary hypertension. PVOD/PCH: pulmonary veno-occlusive disease and/or pulmonary capillary haemangiomatosis; PAH: pulmonary arterial hypertension. 
hypertension [21-26]. In contrast, few cases of PAH in endoglin mutants have been reported, despite the observation that endoglin and ACVRL1 mutations are present in a comparable proportion in the population. This suggests a less potent association between endoglin mutations and PAH [23, 24, 27]. Because of the early development of PAH and the later onset penetrance of HHT features in ACVRL1 mutation carriers, severe PAH can present without any clinical evidence of HHT [22].

In 2009 and 2011, respectively, SHINTANi et al. [28] and NAsim et al. [29] described two cases of PAH associated with Smad8 mutation, one case of PAH associated with Smad1 mutation and one case of PAH associated with Smad5 mutation (figure 1). Smad9, Smad5 and Smad1 genes encode for Smad8, Smad1 and Smad5 intracellular proteins, respectively, which transduce signals from TGF- $\beta$ ligands to the nucleus, where they activate downstream gene transcription. Furthermore, HuANG et al. [30] emphasised the potent role of Smad8 mutations in the development of PAH by demonstrating that mouse carriers of a Smad8 mutation had pulmonary vascular remodelling with medial thickening of the distal pulmonary arteries. However, because of the few cases identified, the involvement of these genes in the development of PAH has yet to be confirmed.

In 2012, exome sequencing in a large PAH family identified caveolin-1 (CAV1) as a predisposing gene for $\mathrm{PAH}$ [31] (figure 1). In a replication cohort, CAV1 was sequenced in $260 \mathrm{PAH}$ patients (62 unrelated patients with familial PAH and 198 sporadic cases) leading to identification of only one additional de novo CAV1 mutation carrier [31]. Caveolae are specialised microdomains in the endothelial cell plasma membrane that are rich in cell surface receptors, such as BMPR2, the Src family of kinases, endothelial nitric oxide synthase, integrins and growth factor receptors such as vascular endothelial growth factor receptor 2 and platelet-derived growth factor receptor, and are therefore instrumental in the initiation of cell signalling cascades [32]. The CAV1 gene encodes a protein involved in the formation of caveolae and has been shown to be involved in regulating vascular tone, proliferation and apoptosis. A loss of CAV1 function leads to a reduction in BMPR2 membrane localisation [33].

In 2013, MA et al. [34] identified KCNK3 as a new predisposing gene for PAH by performing whole-exome sequencing in one PAH family (figure 1). In addition, KCNK3 mutations were identified in two (3.2\%) out of 92 unrelated patients with familial PAH and in three (1.3\%) out of 230 patients with sporadic PAH. Mutations in the KCNK3 gene were responsible for the first channelopathy identified in $\mathrm{PAH}$. To date, mutations in the KCNK3 gene have been associated only with sporadic and familial PAH. The KCNK3 gene encodes KCNK3, a pH-sensitive and non-voltage-dependent outward rectifier potassium channel, which participates in the regulation of plasma membrane resting potential in several cell types, including human pulmonary arterial smooth muscle cells. The decrease in KCNK3 activity with mutations probably causes depolarisation of the resting membrane potential, which could lead to vasoconstriction and pulmonary artery remodelling.

In 2013, Kerstjens-Frederikse et al. [35] identified that the TBX4 gene was involved in the development of $\mathrm{PAH}$ in children who presented with $\mathrm{PAH}$ and dysmorphic features. In addition, they described one case of an adult with PAH carrying a TBX4 mutation. In 2016, LEvy et al. [36] demonstrated that TBX4 mutations are present in $7.5 \%$ of patients in the French paediatric PAH cohort (figure 1). TBX4 mutations are well known to be responsible for the small patella syndrome, also called the coxopodopatellar syndrome, which comprises anomalies of the patella, pelvis, foot and femur to variable degrees. The role of TBX4 in the development of the pulmonary vasculature is insufficiently known; however, it was reported that TBX4 could influence the activity of members of the fibroblast growth factor, Wnt and BMP pathways that link TBX4 mutations to the TGF- $\beta$ signalling pathway [37].

Mutations in all known PAH-predisposing genes are transmitted as an autosomal dominant trait with incomplete penetrance. In the case of BMPR2 mutations, penetrance has been estimated to be $14 \%$ for males and $42 \%$ for females [38]. To date, it has not been possible to determine the penetrance of mutations in other PAH predisposing genes due to the low number of carriers of such mutations.

In the latest European Society of Cardiology (ESC)/European Respiratory Society (ERS) guidelines [39], patients carrying a mutation in a PAH-predisposing gene (BMPR2 and/or other mutations) and patients with a family history of $\mathrm{PAH}$ were grouped under the term "heritable $\mathrm{PAH}$ " in group 1 of the clinical classification of pulmonary hypertension.

\section{Heritable pulmonary veno-occlusive disease and pulmonary capillary haemangiomatosis}

In 1988 and before the discovery of the predisposing gene factor for pulmonary veno-occlusive disease and pulmonary capillary haemangiomatosis (PVOD/PCH), LANGLEBEN et al. [40] described the first familial case of PCH and supposed that the inheritance pattern of PCH was autosomal recessive. In 2014, bi-allelic EIF2AK4 mutations (coding for eukaryotic translation initiation factor $2 \alpha$ kinase 4 ) were demonstrated to predispose to PVOD/PCH. Mutations in the EIF2AK4 gene are transmitted as an autosomal recessive trait 
with an unknown penetrance [41-43]. Distinguishing PVOD/PCH from $\mathrm{PAH}$ on clinical grounds can be challenging, since physical and haemodynamic findings are broadly similar. However, the presence of EIF2AK4 mutations could help to diagnose $\mathrm{PVOD} / \mathrm{PCH}$ in patients with precapillary pulmonary hypertension [44]. Histological examination of the lungs from bi-allelic EIF2AK4 mutations carriers revealed extensive occlusion of pulmonary veins by fibrous tissue, intimal thickening of venules and small veins in the lobular septae and localised capillary proliferation. These histological features correspond to the clinical entities of PVOD/PCH, which are currently believed to be manifestations of the same rare underlying condition with an estimated prevalence of less than one case per million [39, 41, 43, 45]. The EIF2AK4 gene is currently the only gene identified in heritable PVOD/PCH. Besides the heritable form, environmental risk factors such as occupational organic solvent exposure and chemotherapy have been associated with the development of PVOD/PCH [46-48].

In table 4 of the latest ESC/ERS guidelines [39], patients with bi-allelic mutations in the EIF2AK4 gene are grouped with the precapillary forms of pulmonary hypertension under the term "pulmonary veno-occlusive disease and/or pulmonary capillary haemangiomatosis" in group 1 of the clinical classification of pulmonary hypertension.

\section{Genetic counselling Counselling for PAH and PVOD/PCH patients}

The establishment of a genetic counselling programme in France (at the French PAH referral centre, Hôpital Bicêtre, Le Kremlin-Bicêtre and at Hôpital Necker Enfants Malades, Paris), enables us to offer genetic screening to all patients with familial and sporadic $\mathrm{PAH}$ or $\mathrm{PVOD} / \mathrm{PCH}$ and to patients with drug and toxin-induced $\mathrm{PAH}$ or $\mathrm{PVOD} / \mathrm{PCH}$ [49]. Genetic analyses using next-generation sequencing are performed in the oncogenetics and angiogenetics laboratory at Hôpital Pitié Salpêtrière (Paris). We sequence BMPR2, ACVRL1, endoglin, CAV1, KCNK3, SMAD9, TBX4 and EIF2AK4 genes for all patients, although there is no biological basis for sequencing EIF2AK4 gene in patients with heritable PAH with a clearly autosomal dominant pattern of inheritance, but this does not represent any additional cost. Moreover, when the inheritance pattern may be either autosomal dominant or autosomal recessive, this technique could enable clarification or confirmation of the diagnosis of $\mathrm{PAH}$ or $\mathrm{PVOD} / \mathrm{PCH}$ (as demonstrated recently by BEST et al. [44]). An identified mutation is then confirmed using Sanger sequencing. Genetic counselling in these centres follows the recommendations of decree 2000-570 (June 23, 2000) of the French guidelines for genetic counselling, which set the conditions for prescribing and conducting reviews of the genetic characteristics of a person and his or her identification by genetic fingerprinting for medical purposes, and was amended to the public health code (table 1).

TABLE 1 French guidelines for genetic counselling: key points of decree 2008-321 of April 4, 2008

The person is informed about the disease characteristics, detection techniques, genetic analysis sensitivity, prevention and treatment possibilities, genetic modality of the disease transmission and consequences for the other family members

Informed written consent is mandatory

Patient aged $<18$ years and adults under guardianship must agree with the genetic testing, whereas the informed written consent must be signed by the legal representative

The genetic counselling must be performed in an individual consultation

For asymptomatic high-risk relatives, the genetic counselling must be performed in an individual consultation. This presymptomatic diagnosis requires a multidisciplinary approach involving geneticists, pulmonologists, genetic counsellors, psychologists and nurses. This team is registered to the biomedical agency and follows their recommendations

Genetic testing can be prescribed in asymptomatic high-risk relatives aged $<18$ years or in adults under guardianship, only if he/she or his/her family can benefit from preventive or curative treatments

Genetic testing is performed under the responsibility of a physician allowed by Article R.1131-9, practicing in one of the institutions listed in Article R.1131-13. This physician is the only one authorised to sign the genetic results

The genetic testing can only be performed in biological laboratories of public health institutions, cancer centres, biological laboratories mentioned in Article L.6211-2 and in biological laboratories of the French blood bank centres authorised by Article R.11301-14

The prescriber must inform directly the person who underwent the genetic testing in an individual consultation

The person who underwent the genetic testing can refuse to know the result

Reproduced from [49] with permission. 
Up to December 2014, at the French PAH Referral Centre in Le Kremlin-Bicêtre, 529 adult PAH patients underwent genetic counselling. Of the patients we tested, 423 were suffering from sporadic PAH and 106 had a familial form of the disease. A mutation was identified in $72(17 \%)$ sporadic PAH patients $(\mathrm{n}=62$ in BMPR2, $\mathrm{n}=9$ in ACVRL1 and $\mathrm{n}=1$ in endoglin) and in $89 \%$ of patients displaying a familial form of PAH ( $\mathrm{n}=89$ BMPR2 mutations, $\mathrm{n}=3$ ACVRL1 mutations and $\mathrm{n}=2$ KCNK3 mutations). No mutations were identified in $11 \%$ of patients with a family history of PAH (figure 2) [49]. In addition, genetic counselling and testing were offered to $100 \mathrm{PVOD} / \mathrm{PCH}$ patients. Bi-allelic mutations in the EIF2AK4 gene were identified in all PVOD/PCH patients with a familial form of the disease $(n=19)$ and in seven (9\%) patients presenting with a sporadic form of PVOD/PCH [49].

In September 2016, Levy et al. [36] (Hôpital Necker Enfants Malades, Paris, France) described the first cohort of paediatric $\mathrm{PAH}$ and $\mathrm{PVOD} / \mathrm{PCH}$ patients. They demonstrated that the paediatric cohort is enriched in ACVRL1 and TBX4 mutations compared to adult cohorts. Indeed, among 40 children with idiopathic and familial PAH, LEVy et al. [36] identified five (12.5\%) carriers of a mutation in the BMPR2 gene, four (10\%) carriers of a mutation in the ACVRL1 gene and three (7.5\%) carriers of a mutation in the TBX4 gene. In addition, they identified three PVOD/PCH children, two (67\%) of whom carried bi-allelic mutations in EIF2AK4 [36].

\section{Counselling for asymptomatic relatives}

When genetic mutations are identified in patients, genetic counselling and predictive testing are offered to their relatives. Predictive testing involves geneticists, pulmonologists, a genetic counsellor, a psychologist and nurses, with a true multidisciplinary approach. During genetic counselling, relatives are informed about several important risks, including the risk of carrying the familial mutation, their risk of developing overt disease due to incomplete penetrance of mutations in $\mathrm{PAH}$ predisposing genes, and the risk of transmission of the mutation to their offspring. Furthermore, information about PAH/PVOD/PCH symptoms, disease characteristics and prognosis is provided.

In a study from the French PAH referral centre, 272 adult relatives requested predictive testing for PAH, in whom we identified $99(36 \%)$ asymptomatic carriers of PAH-predisposing mutations (96 carriers of a BMPR2 mutation, one carrier of an ACVRL1 mutation and two carriers of a KCNK3 mutation [49]. The risk of developing $\mathrm{PAH}$ is estimated to be $14 \%$ for males and $42 \%$ for females among such individuals with predisposing mutations [38].

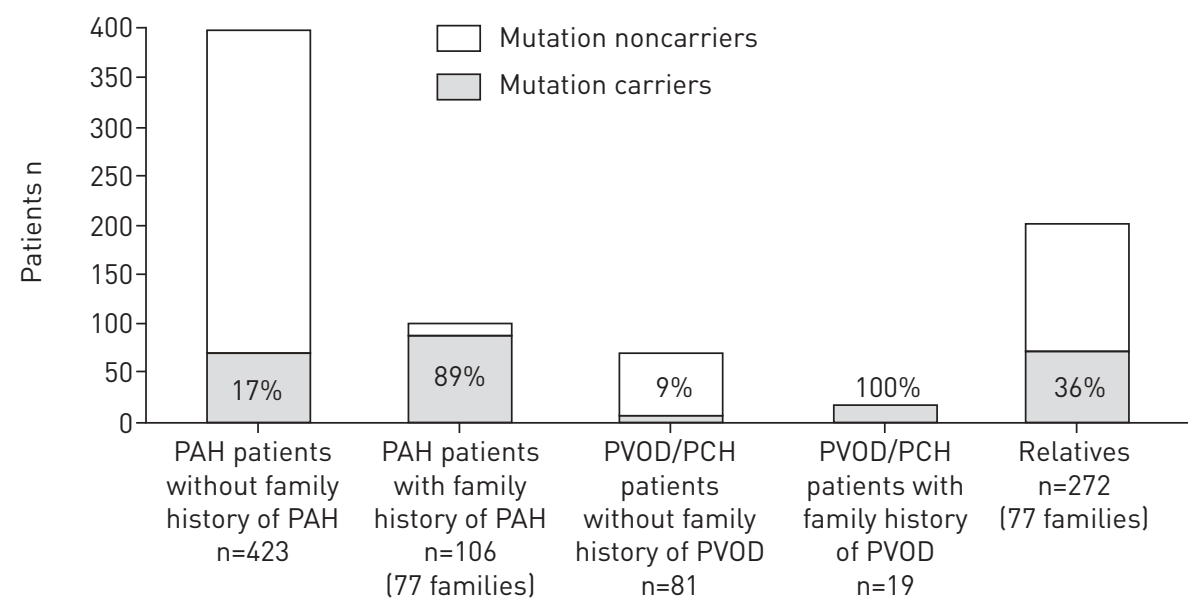

\begin{tabular}{|c|c|c|c|c|c|}
\hline BMPR2 mutation & 62 & 89 (65 families) & 0 & 0 & 96 \\
\hline ACVRL 1 mutation & 9 & 3 (2 families) & - & 0 & 1 \\
\hline ENG mutation & 1 & 0 & - & 0 & - \\
\hline KCNK3 mutation & - & 2 (2 families) & - & - & 2 \\
\hline EIF2AK4 mutations & - & 0 & 7 & 19 (12 families) & - \\
\hline Total mutations & 72 & 94 & 7 & 19 & 99 \\
\hline
\end{tabular}

FIGURE 2 Distribution of mutations in sporadic and familial pulmonary arterial hypertension (PAH) and pulmonary veno-occlusive disease and/or pulmonary capillary haemangiomatosis (PVOD/PCH) patients and asymptomatic relatives in the French PAH network ladult cohort). Reproduced and modified from [49] with permission. 
While predictive testing allows the identification of asymptomatic carriers of a familial mutation and these carriers are at high risk of developing $\mathrm{PAH}$, it is not possible to identify which carriers will develop PAH, due to incomplete penetrance of mutations in PAH predisposing genes. It is not yet known which genetic, environmental or other factors elicit the development of PAH in these mutation carriers, and there are no demonstrated preventative or curative treatments for PAH. Genetic testing of relatives of affected PAH patients might alleviate the uncertainty regarding carrier status for a familial mutation, which is often an unbearable burden. And yet, despite the knowledge of carrier status, mutation carriers often still suffer significantly as a result of the uncertainty over whether they might develop the disease, and if so, when $\mathrm{PAH}$ symptoms will manifest. Thus, the results of genetic testing may have profound psychological consequences, such as fear, anxiety (unpublished data) and guilt, similar to what has been reported in other diseases [50-53].

Asymptomatic carriers frequently worry about illness and death at the slightest sensation of dyspnoea (unpublished data). Our analysis from the French cohort revealed that genetic testing results have consequences for relatives who do not carry the familial mutation. Noncarriers may experience feelings of guilt, anger, cowardice, injustice and abandonment. For all the above reasons, genetic testing in PAH is controversial and is subject to debate. However, there could be benefits to genetic testing and early detection of PAH since it has been demonstrated that early treatment may improve clinical characteristics and could prevent deterioration in patients who have PAH [54-56]. Therefore, presymptomatic screening of individuals with known mutations in PAH-predisposing genes could potentially lead to earlier diagnosis and treatment of PAH. Considering the above, the 2015 ESC/ERS guidelines currently recommend: "in individuals who test positive for $\mathrm{PAH}$-causing mutations and first degree relatives of heritable $\mathrm{PAH}$, cases may be considered to have an annual screening echocardiogram (IIb-C)" [39]. Therefore, at the French $\mathrm{PAH}$ referral centre, we offer a programme for all asymptomatic mutation carriers in order to define the optimal screening strategy and the frequency of screening in these asymptomatic mutation carriers (Screening of Pulmonary Arterial Hypertension in BMPR2 Mutation Carriers (DELPHI-2) study; ClinicalTrials.gov identifier NCT01600898). The forthcoming results from this study should clarify certain issues such as the optimal screening strategies to detect the disease at an early phase and predictors of progression to $\mathrm{PAH}$ in asymptomatic $B M P R 2$ carriers.

To date, in France, predictive testing for children aged $<18$ years remains a matter of debate, because of the absence of preventive and curative treatments in $\mathrm{PAH} / \mathrm{PVOD} / \mathrm{PCH}$. Therefore, no genetic testing for $\mathrm{PAH} / \mathrm{PVOD} / \mathrm{PCH}$ is currently offered to asymptomatic children aged $<18$ years.

\section{Pre-implantation genetic diagnosis}

The identification of a BMPR2 mutation may lead the carrier to consider prenatal diagnosis or pre-implantation genetic diagnosis. These two techniques are used in other diseases such as Huntington's disease or cystic fibrosis to avoid the birth of a child carrying a mutation associated with a serious and life-threatening medical condition, but they remain controversial in PAH because of the low penetrance of BMPR2 mutations. Prenatal diagnosis can detect fetal mutation carrier status in utero, so that if a mutation is found, a medical abortion could be considered. In contrast, pre-implantation genetic diagnosis is a medically assisted reproduction technique where only embryos that are known to not be carriers of the familial mutation are selected and implanted. Because BMPR2 mutations have incomplete penetrance, and abortion can potentially have a negative impact on parents, we favour pre-implantation genetic diagnosis in heritable PAH after a multidisciplinary discussion. Currently, five children from two couples in which the males were carriers of a BMPR2 mutation followed in the French PAH referral centre have been born thanks to pre-implantation genetic diagnosis. The first case was published by our group in 2012 [57].

Regarding PVOD/PCH, so far only heterozygous carriers of EIF2AK4 have been identified, but they do not appear to be at risk of developing disease, whereas all bi-allelic mutation carriers seems to manifest disease. Therefore, prenatal or pre-implantation genetic diagnosis does not concern heterozygous carriers of EIF2AK4 because of the autosomal recessive inheritance pattern (with the exception of in families with consanguinity).

\section{Phenotype-genotype correlation}

Characteristics of patients with a BMPR2 mutation

PAH patients carrying a BMPR2 mutation develop the disease 7-10 years earlier than noncarriers, have more severe haemodynamic variables at the time of diagnosis and are less likely to respond to acute vasodilator testing $[8,11,13,22,58]$. In an international observational study, EvANS et al. [13] demonstrated that, in patients with idiopathic, familial and anorexigen-associated PAH, the presence of a $B M P R 2$ mutation is associated with an increased risk of death or lung transplantation. In another study, Austin et al. [59] demonstrated the implication of particular BMPR2 mutation types (missense, truncating, 
large rearrangement or splice defect) in the phenotypic expression of the disease, a result that was not confirmed in the French cohort [60]. Finally, since PAH mostly occurs in females irrespective of BMPR2 mutation status, it has been suggested that oestrogens and oestrogen metabolism might play a role in the pathogenesis of PAH $[59,61]$.

\section{Characteristics of patients with an ACVRL1 mutation}

In an analysis of PAH patients carrying an ACVRL1 mutation, it was found that these patients were significantly younger at PAH diagnosis compared to those patients with PAH who had a BMPR2 mutation and PAH patients without an identified mutation [22]. PAH patients with an ACVRL1 mutation have less severe haemodynamics at diagnosis compared to BMPR2 mutation carriers, but have shorter survival when compared with other patients despite similar treatment [22], suggesting a more rapid progression of disease in ACVRL1 mutation carriers [22]. Although ACVRL1 mutations predispose to HHT as well, PAH may develop in ACVRL1 mutation carriers without any features of HHT. Therefore, PAH may be the first or the only manifestation of HHT [22].

\section{Characteristics of patients carrying bi-allelic EIF2AK4 mutations}

$\mathrm{PVOD} / \mathrm{PCH}$ occurring in patients carrying bi-allelic EIF2AK4 mutations is characterised by a younger age at diagnosis compared to noncarriers $(25.7 \pm 10.0$ years versus $58.4 \pm 15.5$ years; $\mathrm{p}<0.0001)$ [52]. Regardless of mutation status, all $\mathrm{PVOD} / \mathrm{PCH}$ patients presented with severe clinical, functional, haemodynamic impairment, radiological abnormalities on high-resolution computed tomography (septal lines, ground-glass opacities and lymph node enlargement), low diffusing capacity of the lung for carbon monoxide and hypoxaemia [62]. 22 (81\%) of the EIF2AK4 mutation carriers and 63 (94\%) noncarriers received therapy approved for PAH. Drug-induced pulmonary oedema occurred in five (23\%) of the treated EIF2AK4 mutation carriers and $13(21 \%)$ of treated noncarriers. A mild improvement was observed with PAH therapy in the PVOD/PCH mutation noncarriers, as reported previously $[45,63,64]$. However, a poor response to specific $\mathrm{PAH}$ therapies in bi-allelic mutation carriers was demonstrated, with a very small proportion of patients (three out of 64) reaching the low-risk criteria for mortality proposed for PAH in the European pulmonary hypertension guidelines [39]. Overall, this translated to a dismal prognosis with death or lung transplantation occurring in most PVOD/PCH cases within the first months or years of diagnosis. Indeed, event-free survival (death or transplantation) at 1 and 3 years were $63 \%$ and $32 \%$, respectively, in EIF2AK4 mutation carriers, and 75\% and 34\%, respectively, in noncarriers [62].

\section{Conclusion}

In conclusion, the past 20 years have been marked by the discovery of genes involved in the development of heritable forms of pulmonary hypertension and by the development of genetic counselling. Currently, these discoveries help clinicians to better characterise the phenotype of pulmonary hypertension patients in order to improve clinical care, and allow informed decisions for patients and family members involving family planning, presymptomatic screening and early management.

\section{References}

1 Dresdale DT, Michtom RJ, Schultz M. Recent studies in primary pulmonary hypertension, including pharmacodynamic observations on pulmonary vascular resistance. Bull NY Acad Med 1954; 30: 195-207.

2 Loyd JE, Primm RK, Newman JH. Familial primary pulmonary hypertension: clinical patterns. Am Rev Respir Dis 1984; 129: 194-197.

3 Nichols WC, Koller DL, Slovis B, et al. Localization of the gene for familial primary pulmonary hypertension to chromosome 2q31-32. Nat Genet 1997; 15: 277-280.

4 Morse JH, Jones AC, Barst RJ, et al. Mapping of familial primary pulmonary hypertension locus (PPH1) to chromosome 2q31-q32. Circulation 1997; 95: 2603-2606.

5 Lane KB, Machado RD, Pauciulo MW, et al. Heterozygous germline mutations in BMPR2, encoding a TGF- $\beta$ receptor, cause familial primary pulmonary hypertension. Nat Genet 2000; 26: 81-84.

6 Deng Z, Morse JH, Slager SL, et al. Familial primary pulmonary hypertension (gene PPH1) is caused by mutations in the bone morphogenetic protein receptor-II gene. Am J Hum Genet 2000; 67: 737-744.

7 Machado RD, Eickelberg O, Elliott CG, et al. Genetics and genomics of pulmonary arterial hypertension. $J \mathrm{Am}$ Coll Cardiol 2009; 54: Suppl. 1, S32-S42.

8 Rosenzweig EB, Morse JH, Knowles JA, et al. Clinical implications of determining BMPR2 mutation status in a large cohort of children and adults with pulmonary arterial hypertension. J Heart Lung Transplant 2008; 27: 668-674.

9 Thomson JR, Machado RD, Pauciulo MW, et al. Sporadic primary pulmonary hypertension is associated with germline mutations of the gene encoding BMPR-II, a receptor member of the TGF- $\beta$ family. J Med Genet 2000; 37: $741-745$.

10 Thomson J, Machado R, Pauciulo M, et al. Familial and sporadic primary pulmonary hypertension is caused by BMPR2 gene mutations resulting in haploinsufficiency of the bone morphogenetic protein tùype II receptor. $J$ Heart Lung Transplant 2001; 20: 149.

11 Sztrymf B, Coulet F, Girerd B, et al. Clinical outcomes of pulmonary arterial hypertension in carriers of BMPR2 mutation. Am J Respir Crit Care Med 2008; 177: 1377-1383. 
12 Girerd B, Montani D, Jaïs X, et al. Genetic counselling in a national referral centre for pulmonary hypertension. Eur Respir J 2016; 47: 541-552.

13 Evans JDW, Girerd B, Montani D, et al. BMPR2 mutations and survival in pulmonary arterial hypertension: an individual participant data meta-analysis. Lancet Respir Med 2016; 4: 129-137.

14 Souza R, Humbert M, Sztrymf B, et al. Pulmonary arterial hypertension associated with fenfluramine exposure: report of 109 cases. Eur Respir J 2008; 31: 343-348.

15 Humbert M, Deng Z, Simonneau G, et al. BMPR2 germline mutations in pulmonary hypertension associated with fenfluramine derivatives. Eur Respir J 2002; 20: 518-523.

16 Guttmacher AE, Marchuk DA, White RI Jr. Hereditary hemorrhagic telangiectasia. N Engl J Med 1995; 333: 918-924.

17 Shovlin CL, Letarte M. Hereditary haemorrhagic telangiectasia and pulmonary arteriovenous malformations: issues in clinical management and review of pathogenic mechanisms. Thorax 1999; 54: 714-729.

18 Shovlin CL, Jackson JE, Bamford KB, et al. Primary determinants of ischaemic stroke/brain abscess risks are independent of severity of pulmonary arteriovenous malformations in hereditary haemorrhagic telangiectasia. Thorax 2008; 63: 259-266

19 Begbie ME, Wallace GMF, Shovlin CL. Hereditary haemorrhagic telangiectasia (Osler-Weber-Rendu syndrome): a view from the 21st century. Postgrad Med J 2003; 79: 18-24.

20 Govani FS, Shovlin CL. Hereditary haemorrhagic telangiectasia: a clinical and scientific review. Eur J Hum Genet 2009; 17: 860-871

21 Trembath RC, Thomson JR, Machado RD, et al. Clinical and molecular genetic features of pulmonary hypertension in patients with hereditary hemorrhagic telangiectasia. N Engl J Med 2001; 345: 325-334.

22 Girerd B, Montani D, Coulet F, et al. Clinical outcomes of pulmonary arterial hypertension in patients carrying an ACVRL1 (ALK1) mutation. Am J Respir Crit Care Med 2010; 181: 851-861.

23 Harrison RE, Flanagan JA, Sankelo M, et al. Molecular and functional analysis identifies ALK-1 as the predominant cause of pulmonary hypertension related to hereditary haemorrhagic telangiectasia. $J$ Med Genet 2003; 40: 865-871.

24 Harrison RE, Berger R, Haworth SG, et al. Transforming growth factor- $\beta$ receptor mutations and pulmonary arterial hypertension in childhood. Circulation 2005; 111: 435-441.

25 Abdalla SA, Gallione CJ, Barst RJ, et al. Primary pulmonary hypertension in families with hereditary haemorrhagic telangiectasia. Eur Respir J 2004; 23: 373-377.

26 Fujiwara M, Yagi H, Matsuoka R, et al. Implications of mutations of activin receptor-like kinase 1 gene (ALK1) in addition to bone morphogenetic protein receptor II gene (BMPR2) in children with pulmonary arterial hypertension. Circ J 2008; 72: 127-133.

27 Chaouat A, Coulet F, Favre C, et al. Endoglin germline mutation in a patient with hereditary haemorrhagic telangiectasia and dexfenfluramine associated pulmonary arterial hypertension. Thorax 2004; 59: 446-448.

28 Shintani M, Yagi H, Nakayama T, et al. A new nonsense mutation of SMAD8 associated with pulmonary arterial hypertension. J Med Genet 2009; 46: 331-337.

29 Nasim MT, Ogo T, Ahmed M, et al. Molecular genetic characterization of SMAD signaling molecules in pulmonary arterial hypertension. Hum Mutat 2011; 32: 1385-1389.

30 Huang Z, Wang D, Ihida-Stansbury K, et al. Defective pulmonary vascular remodeling in Smad8 mutant mice. Hum Mol Genet 2009; 18: 2791-2801.

31 Austin ED, Ma L, LeDuc C, et al. Whole exome sequencing to identify a novel gene (caveolin-1) associated with human pulmonary arterial hypertension. Circ Cardiovasc Genet 2012; 5: 336-343.

32 Mathew R. Pathogenesis of pulmonary hypertension: a case for caveolin-1 and cell membrane integrity. Am Physiol Heart Circ Physiol 2014; 306: H15-H25.

33 Wertz JW, Bauer PM. Caveolin-1 regulates BMPRII localization and signaling in vascular smooth muscle cells. Biochem Biophys Res Commun 2008; 375: 557-561.

34 Ma L, Roman-Campos D, Austin ED, et al. A novel channelopathy in pulmonary arterial hypertension. $N$ Engl Med 2013; 369: 351-361.

35 Kerstjens-Frederikse WS, Bongers EMHF, Roofthooft MTR, et al. TBX4 mutations (small patella syndrome) are associated with childhood-onset pulmonary arterial hypertension. J Med Genet 2013; 50: 500-506.

36 Levy M, Eyries M, Szezepanski I, et al. Genetic analyses in a cohort of children with pulmonary hypertension. Eur Respir J 2016; 48: 1118-1126.

37 Rodriguez-Esteban C, Tsukui T, Yonei S, et al. The T-box genes Tbx4 and Tbx5 regulate limb outgrowth and identity. Nature 1999; 398: 814-818.

38 Larkin EK, Newman JH, Austin ED, et al. Longitudinal analysis casts doubt on the presence of genetic anticipation in heritable pulmonary arterial hypertension. Am J Respir Crit Care Med 2012; 186: 892-896.

39 Galiè N, Humbert M, Vachiery J-L, et al. 2015 ESC/ERS Guidelines for the diagnosis and treatment of pulmonary hypertension: The Joint Task Force for the Diagnosis and Treatment of Pulmonary Hypertension of the European Society of Cardiology (ESC) and the European Respiratory Society (ERS). Eur Respir J 2015; 46: 903-975.

40 Langleben D, Heneghan JM, Batten AP, et al. Familial pulmonary capillary hemangiomatosis resulting in primary pulmonary hypertension. Ann Intern Med 1988; 109: 106-109.

41 Eyries M, Montani D, Girerd B, et al. EIF2AK4 mutations cause pulmonary veno-occlusive disease, a recessive form of pulmonary hypertension. Nat Genet 2014; 46: 65-69.

42 Tenorio J, Navas P, Barrios E, et al. A founder EIF2AK4 mutation causes an aggressive form of pulmonary arterial hypertension in Iberian Gypsies. Clin Genet 2014; 88: 579-583.

43 Best DH, Sumner KL, Austin ED, et al. EIF2AK4 mutations in pulmonary capillary hemangiomatosis. Chest 2014; 145: 231-236.

44 Best DH, Sumner KL, Smith BP, et al. EIF2AK4 mutations in patients diagnosed with pulmonary arterial hypertension. Chest 2017; 151: 821-828.

45 Montani D, Lau EM, Dorfmüller P, et al. Pulmonary veno-occlusive disease. Eur Respir J 2016; 47: 1518-1534.

46 Montani D, Lau EM, Descatha A, et al. Occupational exposure to organic solvents: a risk factor for pulmonary veno-occlusive disease. Eur Respir J 2015; 46: 1721-1731. 

agents. Am J Pathol 2015; 185: 356-371.

48 Perros F, Günther S, Ranchoux B, et al. Mitomycin-induced pulmonary veno-occlusive disease: evidence from human disease and animal models. Circulation 2015; 132: 834-847.

49 Girerd B, Montani D, Jaïs X, et al. Genetic counselling in a national referral centre for pulmonary hypertension. Eur Respir J 2016; 47: 541-552.

50 Gargiulo M, Lejeune S, Tanguy M-L, et al. Long-term outcome of presymptomatic testing in Huntington disease. Eur J Hum Genet 2009; 17: 165-171.

51 Charron P, Héron D, Gargiulo M, et al. Genetic testing and genetic counselling in hypertrophic cardiomyopathy: the French experience. J Med Genet 2002; 39: 741-746.

52 Smith CO, Lipe HP, Bird TD. Impact of presymptomatic genetic testing for hereditary ataxia and neuromuscular disorders. Arch Neurol 2004; 61: 875-880.

53 Borreani C, Manoukian S, Bianchi E, et al. The psychological impact of breast and ovarian cancer preventive options in BRCA1 and BRCA2 mutation carriers. Clin Genet 2014; 85: 7-15.

54 Humbert M, Sitbon O, Chaouat A, et al. Survival in patients with idiopathic, familial, and anorexigen-associated pulmonary arterial hypertension in the modern management era. Circulation 2010; 122: 156-163.

55 Humbert M, Sitbon O, Yaïci A, et al. Survival in incident and prevalent cohorts of patients with pulmonary arterial hypertension. Eur Respir J 2010; 36: 549-555.

56 Galiè N, Rubin L, Hoeper M, et al. Treatment of patients with mildly symptomatic pulmonary arterial hypertension with bosentan (EARLY study): a double-blind, randomised controlled trial. Lancet 2008; 371: 2093-2100.

57 Frydman N, Steffann J, Girerd B, et al. Pre-implantation genetic diagnosis in pulmonary arterial hypertension due to BMPR2 mutation. Eur Respir J 2012; 39: 1534-1535.

58 Elliott CG, Glissmeyer EW, Havlena GT, et al. Relationship of BMPR2 mutations to vasoreactivity in pulmonary arterial hypertension. Circulation 2006; 113: 2509-2515.

59 Austin ED, Phillips JA, Cogan JD, et al. Truncating and missense BMPR2 mutations differentially affect the severity of heritable pulmonary arterial hypertension. Respir Res 2009; 10: 87.

60 Girerd B, Montani D, Eyries M, et al. Absence of influence of gender and BMPR2 mutation type on clinical phenotypes of pulmonary arterial hypertension. Respir Res 2010; 11: 73.

61 West J, Cogan J, Geraci M, et al. Gene expression in BMPR2 mutation carriers with and without evidence of pulmonary arterial hypertension suggests pathways relevant to disease penetrance. BMC Med Genomics 2008; 1: 45 .

62 Montani D, Girerd B, Jaïs X, et al. Clinical phenotypes and outcomes of heritable and sporadic pulmonary veno-occlusive disease: a population-based study. Lancet Respir Med 2017; 5: 125-134.

63 Holcomb BW Jr, Loyd JE, Ely EW, et al. Pulmonary veno-occlusive disease: a case series and new observations. Chest 2000; 118: 1671-1679.

64 Ogawa A, Miyaji K, Yamadori I, et al. Safety and efficacy of epoprostenol therapy in pulmonary veno-occlusive disease and pulmonary capillary hemangiomatosis. Circ J 2012; 76: 1729-1736. 